\title{
El léxico de los espacios ganaderos en la documentación del sur de Ávila (siglo XV) ${ }^{*}$
}

The lexicon of livestock spaces in the documentation of southern Ávila (15th century)

\author{
M. ${ }^{a}$ NIEVES SÁNCHEZ GONZÁLEZ DE HERRERO \\ Universidad de Salamanca-IEMYRhd \\ dimes@usal.es
}

\begin{abstract}
Resumen: El presente trabajo se basa en un corpus documental de la actual provincia de Ávila (siglo $\mathrm{XV}$ ) y expone los nombres presentes en estos testimonios de las áreas en las que se alimenta habitualmente el ganado: alixares, baldio, dehesa, echo(s), mangadilla, monte, pasto $(s)$, prado $(s)$, sierra(s) y yerbas. Se revisa el significado correspondiente de cada una de las voces en distintas fuentes lexicográficas y se comprueba su presencia o no en otros corpus coetáneos con el fin de establecer su posible extensión geográfica. De manera secundaria, se valora la validez de las fuentes lexicográficas y los estudios de historiadores a la hora de acercarnos a este tipo de léxico.

Palabras clave: documentación medieval; historia del castellano; lexicografía histórica.

Abstract: The present work is based on a documentation corpora from the current province of Ávila (15th century) and expounds the nouns present in these testimonies from the areas in which cattle usually feeds: alixares, baldio, dehesa, echo(s), mangadilla, monte, pasto $(s)$, prado $(s), \operatorname{sierra}(s)$ and yerbas. All meanings are reviewed on each of the entries in different lexicographical sources, and it is verified whether or not their presence shows up in other contemporary corpora in order to establish its possible geographical extension. Secondly, the validity of lexicographical sources and studies made by historians are assessed when approaching this type of lexicon.

Key words: Medieval Documentation; History of Castilian; Historical Lexicography.
\end{abstract}

Fecha de presentación: 12/09/2019 Fecha de aceptación: 05/12/2019

\section{INTRODUCCIÓN}

La finalidad de este trabajo es revisar el léxico contenido en documentos abulenses del siglo XV referido a espacios relacionados con la ganadería, naturales o creados por intervención humana y, de manera específica, el que nombra áreas en donde se alimenta habitualmente el ganado. Nos proponemos analizar este léxico con una perspectiva descriptiva y comparativa para, a partir del manejo de fuentes coetáneas, observar su distribución, aunque sea aproximada, por otras áreas peninsulares.

\footnotetext{
* Este trabajo se enmarca en el proyecto Variación lingüistica en la documentación de Castilla y León. La documentación medieval abulense: la zona de transición. Edición y estudio, financiado por la Junta de Castilla y León (SA051G18).

M. ${ }^{a}$ NIEVES SÁNCHEZ GONZÁLEZ DE HERRERO, «El léxico de los espacios ganaderos en la documentación del sur de Ávila (siglo XV)», Revista de Lexicografia, XXV (2019), pp. 59-78 ISSN: 1134-4539, e-ISSN: 2603-6673. DOI: ttps://doi.org/10.17979/rlex.2019.25.0.5738
} 
Somos conscientes de la limitación de la exposición, que procede en buena medida de la propia limitación de las fuentes. Los testimonios de los que disponemos nos ofrecen un determinado material, más o menos parcial —no podemos saberlo con exactitud - que tomamos como punto de partida y, a partir de él, acudimos a la consulta de otras colecciones documentales que, como ya señaló Sánchez-Prieto Borja (2010: 272273), son muy heterogéneas por su alcance y objetivos y no llegan a cubrir, ni mucho menos, el espacio ocupado hoy por el español. Nos servimos también de distintas fuentes lexicográficas con la intención de acercarnos al sentido de esta serie de palabras pertenecientes a una parcela concreta de un corpus de pequeño dominio. El recorrido nos permitirá en cierto modo comprobar el valor de las fuentes con las que contamos.

\section{CORPUS}

En los últimos cinco años el grupo GedHYTAS, (Grupo de Estudio de Documentos Históricos y Textos Antiguos de la Universidad de Salamanca) $)^{1}$, ha editado y trabajado con documentación medieval abulense. Las particularidades de las hablas del sur de la provincia, que pueden encuadrarse entre las variedades meridionales peninsulares, dentro de las de la comunidad castellano-leonesa, nos llevaron a interesarnos por su historia y, en consecuencia, a buscar los primeros testimonios de la zona. Fruto de este trabajo ha sido la edición, siguiendo los criterios de la red CHARTA, con el estudio correspondiente, de Codomsa, Corpus de Documentación Medieval del Sur de Ávila. El corpus está integrado por 79 documentos anteriores a 1500, 65 procedentes del Archivo Municipal de Mombeltrán (AMM), el único del sur de Ávila que conserva originales anteriores a 1500, y 14 del Archivo de la Casa Ducal de Alburquerque, depositados en el Archivo Histórico Municipal de Cuéllar (AHMC), Segovia. De los primeros, 12 tienen data cronológica en la primera mitad del siglo y 53 en la segunda; 56 están emitidos en el mismo Mombeltrán, 2 en aldeas de la villa (Lanzahíta y la desaparecida Las Torres), 2 en Arenas de San Pedro, 1 en La Adrada y 4 carecen de data tópica, aunque el contenido hace pensar en Mombeltrán o en Arenas de San Pedro. De los 14 conservados en el Archivo de la Casa Ducal de Alburquerque, datados todos entre 1449 y 1500, 10 tienen data tópica en Mombeltrán, 3 en La Adrada y 1 en Lanzahíta. La tipología es variada, con predominio de documentos de concejo, que incluyen, entre otros, cartas de poder y de procuración, de ventas, de finiquito, pleitos y sentencias, acuerdos entre vecinos y concejo, cuentas y recaudación de impuestos o delimitación de territorios jurisdiccionales.

En la actualidad y como continuación, estamos trabajando en el Corpus de Documentos de Ávila en la Hispanic Society of America, CODAHSA, que incluye testimonios de los siglos XV y XVI de zonas abulenses también meridionales (Guisando, monasterio de San Jerónimo de Guisando, ya en el área lingüística de transición) y otras más al norte, como Fontiveros, o Cantiveros; el corpus está en proceso de elaboración, pero tenemos ya algunos testimonios transcritos. En este caso contamos con cartas de cambio o trueque de tierras, confirmaciones de vecindad del monasterio de San Jerónimo de Guisando y apeamiento de heredades y bienes del cabildo de la catedral de Ávila en Fontiveros.

\footnotetext{
${ }^{1}$ Grupo de investigación reconocido por la Comisión Permanente del Consejo de Gobierno de la Universidad de Salamanca en sesión celebrada el 25 de mayo de 2012.
} 
Los documentos que manejamos pertenecen a fondos monásticos y municipales, vinculados a tradiciones locales ${ }^{2}$. Los escribanos del primer corpus citado parecen ser de la zona sur de Ávila; al menos lo son los pocos que mencionan su procedencia; en cambio, los del segundo se intitulan escribanos públicos de Ávila. En este trabajo nos serviremos de documentos de ambos corpus, señalando los casos en que alguno de los vocablos se recoge en uno solo.

\section{LA IMPORTANCIA DE LA GANADERÍA}

Las frecuentes menciones a espacios reservados para el ganado, así como las peticiones o las disputas por usurpaciones o por disponer del derecho a usar estos espacios que reflejan los distintos testimonios, prueban el valor de la actividad ganadera para la economía local y para la subsistencia de los campesinos. A lo largo de los siglos XII y XIII ya se había producido un gran desarrollo de la ganadería en la España cristiana, desarrollo que benefició sobre todo a los señores, propietarios de grandes rebaños; para los campesinos, en cambio, el ganado estaba destinado al autoconsumo, a labores de tiro, acarreo y trabajo de campo o a la producción de lana y cuero con los que confeccionar vestidos y calzado; no obstante, «el papel de la ganadería en las explotaciones campesinas [...] determina que una parte de las explotaciones esté compuesta por terrenos y derechos de pasto. Algunos son individuales, otros son colectivos» (Álvarez Borge, 2003: 30-31).

Por lo que se refiere a la actual provincia de Ávila, es bien conocida la importancia de la ganadería en su territorio en la época bajomedieval. Tanto las condiciones físicas como la historia de la repoblación concejil, junto con otros factores, favorecieron la vocación pecuaria de estas tierras, característica también de otras regiones del centro peninsular (Monsalvo Antón, 2002: 139).

Los estudios históricos nos muestran una situación bien diferenciada entre el norte y el sur abulense en la época bajomedieval. El norte contaba con un amplio territorio en el que existía un buen desarrollo de explotaciones agrícolas; la temprana repoblación y colonización de la zona, la organización de aldeas, la abundancia de núcleos habitados, con sus propios términos delimitados y un nivel medio o medio-alto de población, favorecieron, ya desde los siglos XII y XIII, una amplia extensión del suelo agrícola. En el sur, en cambio, eran pocos los lugares con desarrollo de una agricultura regular, en parte por la tardía colonización, sobre todo de las comarcas de Gredos, pero también por la propia topografía montañosa que se conjugaba con un poblamiento débil (Monsalvo Antón, 2009: 354). En el siglo XV se mantenían las características apuntadas en el norte, mientras que en el sur, a pesar de que hubo transformaciones, con incremento de las actividades agrícolas, no se produjo una alteración significativa de los grandes espacios forestales (Monsalvo Antón, 2009: 358).

Al margen de esta condición natural, el área surabulense, a lo largo de la Baja Edad Media, vio crecer su importancia como lugar de tránsito de los ganados trashumantes: por los puertos del Pico, Serranillos y Mijares trashumaban rebaños de ovejas y de vacas que se mantenían de los pastos comunes y prados abiertos, y también trashuma-

${ }^{2}$ En los fondos del archivo municipal de Mombeltrán se conservan traslados de documentos de cancillería; en los pocos casos en que mencionamos su testimonio como apoyo, dejamos constancia de ello. 
ban hacia el sur los ganados de la villa de Mombeltrán (Martín, 1997: 103). Esta situación implica la necesidad de una organización de los espacios de pasto por parte de las comunidades locales, organización no carente de conflictos, usurpaciones y disputas que se recogen en los testimonios que han llegado hasta nosotros.

Ya que se trataba de una actividad destacada para la economía de la zona y en parte causante de conflictos, vamos a revisar cómo reflejan los documentos los lugares en los que pace o se apacienta el ganado.

\section{LOS TÉRMINOS Y SU DISTRIBUCIÓN}

Tras la lectura atenta de los documentos abulenses, hemos seleccionado los siguientes vocablos: alixares, baldio, dehesa, echo(s), mangadilla, monte, pasto $(s)$, prado $(s)$, $\operatorname{sierra}(s)$ y yerbas ${ }^{3}$; muchos de ellos se nos presentan, en coordinación o en yuxtaposición, en series léxicas que ofrecen relaciones no bien determinadas en sus acepciones. En realidad, fueron estas series léxicas en las que, junto a voces habituales en la documentación castellana de la época, veíamos otras que nos resultaban novedosas, como alixares y echos, las que nos llevaron a interesarnos por esta parcela del léxico.

A primera vista puede apreciarse ya que nombran espacios diferentes entre sí cuya difusión geográfica posiblemente tampoco es homogénea.

\subsection{Monte}

Consideramos en primer lugar voces referidas a espacios no reservados explícitamente al ganado, aunque podían aprovecharse para su estancia y mantenimiento. Es el caso de monte:

el dicho Juan Sánchez [...] en señal de la dicha posesión, cortó ende ciertos ramos de roble con un cochillo; e dixo que, desde allí, a boz de lo suso dicho, e en el dicho nombre del dicho señor condestable e para él, segund dicho es, que tomava e apreendía e tomó e apreendió la posesión real e por alixares el dicho arroyo de Mataasnillos ayuso fasta dar en Tiétar, e otrosí Tiétar arriba fasta llegar al dicho arroyo de la Guija, e en todo lo entremedias del dicho río e camino real suso nombrado, e así mesmo en la peguera que diz que dizen de la Solana, e de los pinares e montes a ella anexos; la cual dicha peguera está en la cuerda de los cerros que diz que dizen del Avantera, que va a dar al arroyo que diz que dizen de las Perdizes (s.f. [1432 noviembre 26-29] (s.1.). AM Mombeltrán, Carpeta 2, n. ${ }^{\circ} 87$ ).

En secuencia con dehesas y prados en un testimonio que en el fragmento que se cita es traslado de una carta del rey Enrique III de Castilla:

ayades por término e por cosa vuestra, para vós otros, todo el término que vós avíades e de que usávades o vos pertenecía en cual quier manera seyendo aldea e con sus dehesas e montes e prados e aguas corrientes, estantes e con todas las casas e poblado e alixares e vezinos e moradores que moran e moraren en todo el dicho término, que lo ayades bien e complida mente segund lo

\footnotetext{
${ }^{3}$ La presencia de algunas de estas palabras en la documentación surabulense (prados, pastos, yervas, dehesa y alixares), ya fue comentada brevemente en Sánchez González de Herrero (2017: 276-279).
} 
teníades e poseíades e poseer devíades o podíades antes que vos yo fiziese villa (Mombeltrán, 1453 agosto 1. AM Mombeltrán, Carpeta 2, n. ${ }^{\circ} 10$ ).

En Castilla, los campesinos solían disfrutar de derechos para aprovechar zonas de titularidad colectiva, los comunales, y la documentación suele referirse a ellas con la voz monte, «que debemos entender con un sentido general de zonas no cultivadas», de las que los campesinos podían obtener recursos naturales como leña, caza o frutos de recolección, además de pastos naturales y, por ejemplo, bellotas (Álvarez Borge, 2003: 31). Aunque algunas áreas forestales de Ávila podían pertenecer a propietarios individuales, lo habitual es que fueran comunales ${ }^{4}$, sobre todo en el sur (Monsalvo Antón, 2002: 142 y 156).

En su segunda acepción, el $D L E$, s.v. lo define como 'tierra inculta cubierta de árboles, arbustos, matas o hierba’. En el Atlas lingüístico de Castilla y León, monte era la voz general en Ávila para 'bosque' (Llorente Pinto, 1997: 93).

\subsection{Sierra}

En una confirmación de vecindad del monasterio de san Jerónimo de Guisando con la ciudad de Ávila encontramos una serie enumerativa, repetida en dos ocasiones, y en las dos montes va en coordinación con sierras:

Por ende que ellos, en nombre de prior e frailes e convento, suplicavan e suplicaron e pedían e pidieron por merced al dicho concejo, justicia, regidores, cavalleros, escuderos [...] que les pluguiese mandar que los dichos sus ganados puedan entrar e pacer de aquí adelante en los alixares e montes e sierras, echos e pastos e términos comunes de la dicha cibdad e su tierra e en todo lo baldio d'ella segund que entran e pacen los ganados de los otros vezinos de la dicha cibdad e su tierra, por que ellos puedan sostener los dichos sus ganados (1461 agosto 27 Ávila, Archivo de la Hispanic Society, Monasterio de San Jerónimo de Guisando).

Mandaron que [...] de aquí adelante en cuales quier alixares e echos $e$ montes e sierras e pastos comunes de la dicha cibdad e su tierra e en todos los términos baldíos d'ella segund e por la forma e manera que entran e pueden entrar los ganados de los vezinos de la dicha cibdad e su tierra (1461 agosto 27 Ávila, Archivo de la Hispanic Society, Monasterio de San Jerónimo de Guisando).

Tal y como recogen los diccionarios actuales, sierra suele denominar 'parte de una cordillera', o 'cordillera de montes o peñascos cortados' (DLE s.v.) y es la voz general en toda Ávila para referirse a 'montaña' (Llorente Pinto, 1997: 72).

Sierras y gargantas, apelativos de descripción topográfica, se mencionan en la documentación abulense como espacios comunales aptos para ser aprovechados por el ganado de la comunidad (Monsalvo Antón, 2002: 173). Este uso, semejante al de

\footnotetext{
${ }^{4}$ Como explica Monsalvo Antón (2002: 159) a propósito de las zonas de pastoreo en la Tierra de Ávila, la característica de los bienes comunes era su disfrute libre y gratuito por la comunidad correspondiente, que podía ser el conjunto de los habitantes de una aldea, el concejo de la aldea, los habitantes de una comarca o los de la ciudad y la Tierra de Ávila, o parte de ellos, según determinadas condiciones. La reglamentación de los usos era muy precisa.
} 
monte como 'tierra o zona no cultivada', no se recoge con facilidad en los corpus consultados, salvo en CORDE siempre en testimonios abulenses, y en un único ejemplo vallisoletano, fechado en 1243, tomado de CODEA $+2015^{5}$ :

E yo, porque la orden e los de Alcaraz ayan siempre abenencia e paz entre sí, mando e establesco que bivan d'esta guisa, que en sus montes e en sus sierras ayan siempre uso de pacer e de cortar comunalmientre los unos en lo de los otros, sacadas end dos defesas (CODEA+2015: 1205).

\subsection{Baldio}

También sirve para el ganado lo baldío, adjetivo usado a veces como sustantivo, dicho de la tierra, 'que no está labrada ni adehesada' (DLE, s.v.).

En el sur de Ávila cada aldea tenía un término propio en el que coexistían los terrenos particulares, los terrenos considerados dehesas boyales o exidos y a veces amplios espacios comunes de uso extensivo, esto es, los baldíos o comunales de cada aldea. Los pastos comunales de cada lugar o concejo podían ser aprovechados por los residentes o los propietarios de la aldea, pero quedaban restringidos para los de fuera de la misma (Monsalvo Antón, 2002: 168).

Este uso de terrenos baldios queda reflejado en el siguiente fragmento perteneciente al testimonio ya citado de 1261 :

Por ende que ellos, en nombre de dicho prior e frailes e convento, suplicavan e suplicaron e pedían e pidieron por merced al dicho concejo, justicia, regidores, cavalleros, escuderos [...] que les pluguiese mandar que los dichos sus ganados puedan entrar e pacer de aquí adelante en los alixares e montes e sierras echos e pastos e términos comunes de la dicha cibdad e su tierra e en todo lo baldío d'ella segund que entran e pacen los ganados de los otros vezinos de la dicha cibdad e su tierra, porque ellos puedan sostener los dichos sus ganados (1461 agosto 27 Ávila, Archivo de la Hispanic Society, Monasterio de San Jerónimo de Guisando).

Son numerosas las ocurrencias de baldio, adjetivo, en textos medievales del CORDE con los significados de 'vano, inútil, desatinado' o con el de 'ocioso' (DCECH, s.v. balde1), pero no aplicado al terreno. Referido ya a la tierra 'que no se labra', en CORDE hasta 1600 aparecen seis testimonios peninsulares en una misma obra (1575-1580). DITECA S.v. recoge abundantes ejemplos del uso, tanto adjetivo como sustantivo, de baldio(s) en este sentido. Y en CODEA+ 2015 encontramos únicamente dos menciones, una en Guadalajara de finales del XV y otra, un poco posterior, en Ávila:

\footnotetext{
${ }^{5}$ En CODEA+2015 comprobamos 270 apariciones de montes, frecuentemente tras, o ante, pastos o prados (también con fuentes y con defesas / dehesas) en secuencias enumerativas, pero no con sierras. Lo mismo sucede en DITECA, donde monte aparece en secuencia con baldio, dehesa, prados y pastos, pero no con sierras. En CORDE, en documentos abulenses del XIV, sierras aparece en las enumeraciones de terrenos comunales para aprovechamiento del ganado, como puede comprobarse en los dos siguientes: «sobre rrazón de los términos e pastos e pinares e sierras e echos comunes que están entrados e tomados a la dicha çibdat de Avila e de su tierra» (1415); «que mostrasen ante vos los títulos e rrecabdos que cada uno dellos dixiese que tenía a los dichos términos e sierras e pastos et pinares e echos, o alguno dellos» (1415).
} 
«que en los tiempos del invierno dexedes e consintades pacer las dichas tres mill cabeças de ganado libremente por los baldios d'esa nuestra villa e su tierra», en Guadalajara, 1491 (CODEA+ 2015: 1470),

«para que ningund vezino del dicho lugar ni de otra parte fuese osado fuese osado a cortar, ni roçar ni labrar en los alixares e baldíos de la dicha cibdad e su tierra», en Ávila, 1520 (CODEA+ 2015: 1432).

\subsection{Prados y pastos}

Posiblemente prados y pastos, juntos o por separado, son dos de las denominaciones más habituales en la documentación notarial, desde sus primeros testimonios, primero en latín (PRATOS, PASCUA), luego en el romance más temprano (prados y pastos), para hacer referencia a espacios destinados al ganado. Su presencia en la documentación del norte peninsular es constante desde fechas tempranas tanto en testimonios leoneses (Morala, 2007), como castellanos (Isasi et al., 2017: 88-91) o navarros y aragoneses (Líbano y Villacorta, 2013: 58) ${ }^{6}$. No faltan en los textos notariales abulenses en los que aparecen en series enumerativas, especialmente pastos, pero no como binomio léxico:

los dichos señores querién apear todas las heredades que tienen en esos dichos lugares, de tierras de pan levar y non levar y viñas y prados y eras y fronteras y otros cuales quier que tengan en esos dichos lugares y en sus términos y en cada uno d'ellos, y que para lo fazer y apear que han menester personas d'esos dichos lugares y de cada uno d'ellos (Fontiveros, 1491 marzo 6. Archivo de la Hispanic Society HC380-441f. 1-14).

dende a dar en un fresno que está junto con el arroyo que viene del prado del Esquerdo e, atravesando el dicho arroyo, dende adelante a dar en un roble que está en mitad del soto (s.1., 1491 junio 7. AMM, c. 2, n. ${ }^{\circ}$ 52).

avía entrado e tomado la posesión vel casi de ciertos términos e caserías e aldeas, que llaman Los Mijares e Gavilanes, e ciertas pegueras e otros términos e pastos que dexieron que son del dicho lugar Torres e de Lançahíta (Lanzahíta, 1432 diciembre 20; AMM, c. 2, n. ${ }^{\circ}$ 3).

sobre razón de asignar cierta propia dehesa de los términos e pastos del dicho monesterio (1455 agosto 12, Archivo de la Hispanic Society, Monasterio de San Jerónimo de Guisando).

La diferencia semántica entre las dos palabras no suele ser clara. Morala (2018: 230) afirma que no se trata de una pareja de sinónimos. Arribas Magro (2012: 601-602) señala, para el binomio latino, que «la diferencia entre prado y pascua está [...] en la intervención humana en la creación de los primeros, mientras que los segundos serían pastos silvestres» ${ }^{7}$. Por su parte Álvarez Borge (2003: 31), en referencia a la situación de los siglos XII y XIII y a propósito del carácter individual o colectivo de los terrenos y dere-

\footnotetext{
${ }^{6}$ En realidad, pueden encontrarse menciones a prados y pastos en testimonios de toda la Península a lo largo de toda la Edad Media; basta consultar el CORDE o CODEA para obtener referencias de la zona que se busque.

${ }^{7}$ Peña Bocos (apud Isasi et al., 2017: 89) contrapone monte o silvae a pratum y afirma que «Los prata, por el contrario, son terrenos deliberadamente preparados y con un claro destino ganadero, puesto que su utilización básica es la producción de heno y, subsidiariamente, el apacentamiento».
} 
chos de pasto, sostiene que los prados suelen ser de propiedad y aprovechamiento individual y añade: «Frecuentemente el campesino dispone de algunas parcelas destinadas a prados, además de las tierras de cereal, las viñas y las huertas; prados que se distinguen en el terrazgo de la aldea por las cercas que los limitan respecto de las tierras de cultivo». En el mismo sentido, Monsalvo Antón (2002: 143) afirma que en Ávila los prados eran los espacios de pasto privados por antonomasia. Podían ser pequeños espacios cercados alrededor de los núcleos habitados, aunque también los había en grandes superficies.

Esta distinción es la que posiblemente reflejan los testimonios que manejamos; de hecho, cuando en escrituras de deslindes se mencionan prados, no es raro que aparezca la referencia a su posesor o posesores, lo que nunca sucede con las menciones a pastos $^{8}$ :

luego en continente apearon un prado que es a La Macarra en que ay dos cuartas, que ha por linderos, de la una parte, prado de la Juan Pamo y, de la otra parte, prado de Alonso de Fontiveros y, de la otra parte, prado de Pero de Mercado y, de la parte de baxo, tierras de la dicha heredad de La Macarra (Fontiveros, 1491 marzo 6. Archivo de la Hispanic Society HC380-441f. 1-14).

luego en continente apearon otra tierra que es al prado oyudo en que ha tres cuartas, que ha por linderos, de la una parte fazia Fontiveros, tierra de Diego de Tapia y, de la otra parte fazia Pascual Grande, prados de los herederos de Alonso Ferrández de la Cava y tierra de los dichos herederos (Fontiveros, 1491 marzo 6. Archivo de la Hispanic Society HC380-441f. 1-14).

a la otra fruente, el prado de La Reoyada, que es de los dichos señores deán y cabildo, en el cual dicho prado puede aver cuatro arançadas, poco más o menos (Fontiveros, 1491 marzo 6. Archivo de la Hispanic Society HC380-441f. 1-14).

Existía además una modalidad de pastoreo que, en palabras de Monsalvo Antón (2002: 147-153), se daba en territorios particulares, también de titularidad individual o familiar, pero que, a diferencia de los privados, estaban sometidos a derechos de otros usuarios no propietarios y podían ser aprovechados por parte de la comunidad en determinadas circunstancias y épocas del año. En este régimen particular se incluyen los llamados prados de bueyes e de heno, con uso particular del 1 de febrero hasta San Andrés de noviembre y luego comunes:

luego en continente apearon otra tierra que es al prado del heno de Cantiveros en que ha tres cuartas, que ha por linderos, de la una parte, tierra de García de la Puebla y, de la otra parte, tierra de los frailes de Santo Tomás (Fontiveros, 1491 marzo 6. Archivo de la Hispanic Society HC380-441f. 1-14).

\subsection{Hierbas}

Como sinónimo de 'pastos' recoge el $D L E$ el plural hierbas, 'pastos que hay en las dehesas para los ganados' (DLE, s.v. hierba, 8$)^{9}$. El $D C E C H$, s.v. hierba, da cuenta de la

\footnotetext{
${ }^{8}$ Llorente Pinto (1997: 74 y 100), al recoger los nombres abulenses de 'erial', en el capítulo dedicado a la agricultura, incluye, entre otros, baldio, erial, cerro, pastizal, en Lanzahíta, y (tierra) de pasto, en Piedralaves; en el correspondiente a la vida pastoril prado es la respuesta en todos los lugares encuestados a la pregunta prado.
} 
acepción secundaria 'veneno', con uso generalmente plural, y a este propósito recoge el juego de palabras que refiere Juan de Valdés en el Diálogo de la Lengua 127.22: «Yervas llamamos en Castilla a lo que acá [ $=$ en Italia] llamáis tóssigo, y también a los pastos adonde se apacientan los ganados [...] Un escudero muy honrado, aviendo arrendado ciertas yervas o pastos en su tierra y no teniendo con qué pagarlas, se ausentó de la tierra, y [...] encargó [...] publicasse que era muerto, «y si os preguntaren — dixo élde qué morí, dezid que de yervas»:

sobre razón de los alixares y yervas de Valdetiétar y la Solana, término y juredición de la dicha villa (Mombeltrán, 1494 junio 9. AMM, c. 2, n. ${ }^{\circ} 63$ ).

\subsection{Dehesa}

Al igual que los prados, las dehesas suelen ser también terrenos acotados, 'tierra generalmente acotada y por lo común destinada a pastos' (DLE, s.v.1); 'campo de yerva donde se apacienta el ganado' (Covarrubias, s.v.):

Juan Sánchez [...] descendió desde la dicha casería e peguera de los dichos Gavilanes fasta la cabeçada de la dehesa que dizen de Rencón de Abades, [...] e andudo de pies por la dicha cabeçada de la dicha dehesa de Rencón de Abades e cortó ende ciertos ramos de un roble con un cochillo (s.f. [1432 noviembre 2629] (s.1.). AM Mombeltrán, Carpeta 2, n. ${ }^{\circ} 87$ ).

todos cuatro junta mente fizieron cierto apuntamiento e capitulación de la forma e manera que se cogiese el dicho montadgo e montadguillo e de qué dehesas ${ }^{10}$ (La Adrada, 1491 noviembre 13 AHM Cuéllar, Carpeta 7, n. ${ }^{\circ} 44$, recto).

luego en continente apearon un prado que es a Cardillejo, el cual afruenta en $l a$ dehesa y en las viñas y se llama la Reguera de tras Cardillejo [...] Y luego en continente apearon otra tierra que es al prado oyudo ${ }^{11}$ en que ha tres cuartas $[\ldots] \mathrm{Y}$ luego en continente apearon otra tierra que comiença desde la Reguera de carra ${ }^{12}$ Cantiveros y rebuelve camino del dicho Cantiveros en que ay diez y seis obradas (Fontiveros, 1491 marzo 6. Archivo de la Hispanic Society HC380-441f. 1-14).

Para Monsalvo Antón (2002: 144), en Ávila, dehesa define «un régimen de aprovechamiento privilegiado, de uso privativo de sus titulares, pero no condiciona que sea un espacio pecuario» y presenta casos de dehesas dehesadas con prados de bueyes y cultivos de cereal.

Los testimonios abulenses hablan en algún caso de dehesas dehesadas y de dehesa boyal, es decir, 'acotadas ${ }^{13}$ en el primero caso y 'destinada al ganado de labor', fun-

\footnotetext{
${ }^{9}$ DEDA, s.v. hierba, recoge en la documentación alfonsí de Castilla la Vieja y Andalucía yerbas, 'pastos para los ganados'. Martín (1997: 79) menciona un privilegio de Alfonso X, fechado en 1273, por el que reconoce oficialmente a la agrupación de los pastores de Castilla, protege los desplazamientos de ganado por las rutas pecuarias y regula el acceso de los rebaños a las yerbas.

${ }^{10}$ En este caso se refleja el pago de un pecho o tributo, el montadgo, al titular o titulares por el uso de las dehesas.

${ }^{11}$ Hoyudo no figura en el DLE, sí hoyoso, 'que tiene hoyos'.

${ }^{12}$ Para carra, 'hacia', voz relacionada con carrera, carril, etc., cf. DCECH, s.v. cara, que la marca como dialectal.

${ }^{13}$ DEDA, s.v. dehesado, aplicado a un lugar o territorio, 'acotado', recoge testimonios en documentos alfonsíes destinados a Castilla y Andalucía de prados defesados y lugares defesados. Los informantes de Mom-
} 
damentalmente bueyes, aunque podía haber un espacio reservado al ganado caballar, en el segundo; la diferencia entre ambas podría residir en el carácter comunal de la segunda, de uso concejil; cada aldea tenía la suya (Monsalvo, 2002: 161 y 2012-2013: 109):

diz que ansí mesmo les es por fuerça y cosa necesaria de soltar sus bueyes y ganados para pacer las yervas y bever las aguas, guardando los panes y las viñas y dehesas dehesadas y semenceras y prados de guadaña que los concejos guardan y acostumbran guardar para sus ganados domados, y que en todos los otros términos y prados do quier que andovieren sus ganados cerriles, que son yeguas y vacas y otros ganados que non son domados, que ellos pueden soltar y pacer con sus bueyes sin pena nin calupnia alguna, que de justicia non se les puede vedar (Mombeltrán, 1499 abril 20. AM Mombeltrán, Carpeta 2, n. $\left.{ }^{\circ} 79\right)^{14}$.

desd'el dicho puerto del Fondo, la cumbre arriba, fasta do dizen el Castillejo e dende fasta la cabeça del Asno e dende adelante fasta do dizen Blasco Chico e dende ayuso fasta la garganta do dizen el Chorro de Blasco Chico e, la garganta ayuso, fasta la dehesa boyal de las Torres (s.f. [1432 noviembre 26-29] (s.l.). AM Mombeltrán, Carpeta 2, n. ${ }^{\circ} 87$ ).

Defesa / dehesa es voz con notable presencia en testimonios bajomedievales peninsulares. En CODEA 2015 para defesa hallamos 75 apariciones en documentos que van del siglo XIII (desde 1211) al XV en Castilla (faltan en la parte leonesa), Aragón y Extremadura por 49 de dehesa, de los siglos XIII al XVIII en La Rioja, Castilla (con inclusión de un testimonio en Salamanca, 1461), Extremadura, Madrid y Toledo. García Sánchez (2007: 152) afirma que el apelativo dehesa, con el valor de 'terreno delimitado', «ha creado innumerables nombres de lugar, algunos de los cuales han pasado a la toponimia de poblaciones». Con variantes, defesa, defessa, deffesa, o deuesa, se recoge en los fueros de Salamanca, Alba de Tormes y Ledesma (Carrasco P. e I., 1997: 485). No encontramos ejemplos de dehesa dehesada y solo 4 de dehesa boyal, 1584, localizados en Arganda del Rey (Madrid). En DITECA son abundantísimos los ejemplos de dehesa (deesas, deessas, deheça, dehesa(s)), con inclusión de dehesa boyal y dehesa de los bueyes.

En el corpus del NDHE, contamos con 2217 ejemplos de dehesa, que van de 1242 a 1999, de los cuales 492 corresponden a la Edad Media, hasta 1499; para dehessa vemos 18, que van del XIII al XVI; defesa, por su parte, se recoge en 240 ocasiones a partir de 1218 hasta finales de la Edad Media ${ }^{15}$; defessa consta 12 veces en testimonios romances hasta 1491. En el mismo corpus aparece dehesa dehesada seis veces, cinco de las cuales están fechadas a finales del siglo XV, (1486 y 1493), en Madrid y la sexta,

beltrán no reconocen el uso de dehesa dehesada, pero ante la pregunta interpretan que puede ser la parte destinada a animales, ya que la dehesa sementera - dicen - es la parte de la finca que se destina a la siembra, a la simiente y cultivo de alimentos para ganado etc.

${ }^{14}$ Este documento es traslado de una provisión real dada por los Reyes Católicos (1498 marzo 9, Alcalá de Henares) ante las demandas presentadas por los carreteros, para que se deje pacer el ganado que llevan en todo el reino.

${ }^{15}$ Las apariciones de defesa en el CNDHE son en realidad 243 y llegan hasta 1915 con dos ejemplos de esa fecha en un libro de historia sobre el abadengo de Sahagún en el que se reproduce documentación antigua. Hay además dos ejemplos del XVI, uno de 1509 que no corresponde al sustantivo y otro de 1575 , un tratado de geografía del reino de Toledo, escrito en el XX, en el que se recoge un documento en el que alternan defesa y dehesa. 
con fecha de 1898, que corresponde a una publicación que recoge las Ordenanzas de Granada. Finalmente, boyal cuenta con 91 ejemplos fechados en 1575, la mayor parte de los casos referidos a dehesa y en menor medida a prado ${ }^{16}$, que tienen continuación en los siglos XIX y XX, junto a dehesa y prado.

\subsection{Mangada/ mangadilla}

De las voces propuestas, solo una ofrece marcación diatópica en el diccionario académico; se trata de mangada, 1. Sal. "prado o pedazo de tierra labrantía largo y estrecho' (DLE, s.v.):

Y luego en continente los dichos apeadores, estando presentes los dichos señores don Pedro de Calatayud, deán, y Bartolomé del Fierro, arcipreste de Ávila, y así mismo Ferrand Coba, vezino del dicho lugar Fontiveros, apearon el prado que dizen de Calongía, con la mangadilla que pertenecía al dicho Ferrand Coba, los cuales dichos apeadores dixeron que la dicha mangadilla es del dicho prado de Calongía, so cargo del dicho juramento que fecho avían, y el dicho Ferrand Coba, que presente estava, dixo que, pues los dichos apeadores dezían y estavan so cargo del dicho juramento, la dicha mangadilla ser del dicho prado de Calongía, que él se desistía y desistió d'ella y la dexava y dexó para agora y siempre jamás a los dichos señores deán y cabildo; en el cual dicho prado de Calongía con la dicha mangadilla ay ocho obradas y una cuarta (Fontiveros, 1491 marzo 6. Archivo de la Hispanic Society HC380-441f. 1-14).

Aparece repetida únicamente en este documento, siempre en forma diminutiva ${ }^{17}$. El carácter descriptivo del testimonio no permite interpretar el significado, pero, al tratarse de un pedazo de tierra anejo a un prado, aunque diferenciado de él, posiblemente deba identificarse con un saliente rectangular del mismo, pues este tipo de salientes de prados y fincas desde antiguo se han comparado a una manga que sobresale del cuerpo principal (Riesco, 2014: 192).

Lamano (s.v. mangada) la define como 'trozo de prado, o de tierra labrantía, largo y estrecho'. Le Men (2007: IV, 585) amplía el área de la voz y afirma que no se trata solo de un salmantinismo, pues, con idéntico valor al marcado por el DLE, está presente «en el occidente de León (Bierzo, Ribera del Órbigo, Cepeda y La Bañeza), en Santander, en La Rioja y en Navarra». Además López de Guereñu (s.v.) la documenta en Álava, concretamente en Lopidana: mangada, 'tierra de labor larga y estrecha'.

\footnotetext{
${ }^{16}$ La fuente que cita el CNDHE es la siguiente: «1575-1580 Anónimo, Relaciones histórico-geográficasestadísticas de los pueblos de España. Reino de Toledo [España] [Carmelo Viñas y Ramón Paz, Madrid, CSIC, 1951-1963] Geografía». En una de las apariciones se lee: «de buen agua, como es uno que llaman Belvis, del cual riegan las guertas que el dicho pueblo tiene en la vega que llaman del mismo nombre, también tiene una dehesa concejil, que llaman boyal, donde libremente sin pena alguna pasta el ganado mayor del pueblo, el cual tiene dos dehesas a censo perpetuo en cada un año cincuenta y tres mil y quinientos maravedís».

${ }^{17}$ La formación de diminutivos en el corpus presenta en general el sufijo -illo, - $a$, hontanillas, mangadilla, pradillo, pardillo, risquillo, etc., el más frecuente en Castilla hasta el siglo XVIII y usual aún hoy en buena parte de Ávila con la excepción de la zona más occidental, que prefiere -ino, - $a$ (Llorente Pinto, 1997: 282).
} 
Son escasos los testimonios medievales de mangada en este sentido en los corpus consultados y los pocos ejemplos con que contamos se localizan precisamente en Ávila $(\text { CORDE })^{18}$.

En definitiva, con alguno de los dos significados que le atribuye el diccionario académico, mangada se documenta en el occidente peninsular, León y Salamanca, extendiéndose hacia el oriente por Cantabria, Álava, La Rioja y Navarra al norte y por Castilla, al menos por Ávila más al sur; hay además testimonios toponímicos de su uso, abundantes sobre todo en Castilla, con continuidad por Cáceres ${ }^{19}$.

\subsection{Alixar(es)}

Una palabra de la nómina de origen árabe es alixar, los alixares, «'country house: farmhouse' and alixar 'Morisco peasant's house' < And. addišár, dissimilatory var. of $\mathrm{Cl}$. Ar. jušār 'drove of horses, with considerable semantic evolution» (Corriente, s.v. adixar and alijar), presente en varios documentos:

Mandaron que [...] de aquí adelante en cuales quier alixares e echos e montes e sierras e pastos comunes de la dicha cibdad e su tierra e en todos los términos baldíos d'ella segund e por la forma e manera que entran e pueden entrar los ganados de los vezinos de la dicha cibdad e su tierra (1461 agosto 27 Ávila, Archivo de la Hispanic Society, Monasterio de San Jerónimo de Guisando).

juez escojido entre partes [...] sobre razón de los alixares y yervas de Valdetiétar y la Solana, término y juredición de la dicha villa de Mombeltr $<a ́>n$ [...] mando que los dichos alixares de Valdetiétar y la Solana que dende aquí adelante para siempre jamás sean de la dicha villa de Mombeltrán y su tierra y sean suyos para los poder pacer y arrendar a cuales quier personas que ellos quisieren $[\ldots]$ e que el dicho señor duque nin sus subcesores de agora para siempre jamás non puedan meter nin mandar meter ganados algunos suyos nin agenos en los dichos alixares a pacer nin puedan perturbar al dicho concejo de la dicha su villa que los puedan pacer y arrendar como quesieren e por bien tovieren (Mombeltrán, 1494 junio 9. AM Mombeltrán, Carpeta 2, n. ${ }^{\circ} 63$ ).

Sobre su significado, contamos con algunas interpretaciones no del todo coincidentes. Según Covarrubias (s.v. alijares) «vale tanto como exidos y salidas espaciosas de los pueblos adonde suele la gente salir a recrearse y holgarse». Como 'terreno inculto' y en pl. 'ejidos' se define en el $D H L E^{120}$; el $D H L E^{2}$ suma dos nuevas: 1. 'cortijo, tierra y casa de

${ }^{18}$ El CORDE recoge únicamente diez apariciones de mangada hasta 1500 en solo dos documentos; el primero, fechado en 1303, cuenta con seis casos; el segundo, de 1415, contiene los cuatro restantes que ofrecen el significado que el $D L E$ atribuye a la palabra y están localizados en Ávila. Los testimonios de 1303 aparecen también en el CNDHE, junto a casi un centenar de ejemplos de Mangada, correspondientes a nombres propios, toponímicos y antroponímicos, que llegan hasta el siglo XX. Sin apariciones en CODEA+2015 ni en DITECA.

${ }^{19}$ Riesco (2014: 192) afirma que son abundantes, especialmente en Castilla, topónimos Las Mangadas y La Mangada, y cita ejemplos de Segovia, Valladolid, Salamanca y Cáceres. Preguntamos a informantes de Mombeltrán si conocían la palabra y la respuesta fue negativa.

${ }^{20}$ Estas son las dos acepciones contenidas en el DHLE ${ }^{1}$ S.V. alijar. En DHLE ${ }^{2}$ S.V. alijar, se dice 2 'Terreno inculto o baldío, generalmente cubierto de monte bajo y arbusto'. 3 'Ejido o terreno de una población, de uso comunal, bien para esparcimiento de sus vecinos, o bien para otros fines prácticos'. 
labor' y 4. pl. 'casas de campo regias, como las que tenían en Granada los reyes moros'. En el diccionario académico de 1770 (NTLLE, s.v.) se lee: «En lo antiguo parece que era tierra o terreno inculto, a cuyo sentido sirve de apoyo el uso freqüente que hoy tiene en toda la Jara de Talavera, en que se llama alixar la tierra inculta, áspera y pedregosa que está vestida de monte baxo y arbustos. Úsase más comúnmente en plural» ${ }^{21}$. En el $D C E C H$, s.v. alijar I, se recuerda que los Alijares granadinos eran una especie de casa de campo que tenían para su placer los sultanes nazaríes en las afueras de la ciudad y se añade que, por lo que se refiere a los testimonios castellanos de alixar como apelativo, citados por el $D H L E^{1}$, «no son seguras ni mucho menos las traducciones 'terreno inculto' y 'ejidos' que les atribuye la Academia; por el contrario, el hecho de mencionarse en ellos alixar junto a cortijos y alquerías lleva a creer que era sinónimo de estas voces ${ }^{22}$.

Desde el punto de vista histórico, Monsalvo (2012-2013: 129) describe los alixares como pastos compartidos por dos o más concejos de villa y tierra, pastos intercomunales o mancomunados entre concejos según pactos de vecindad, áreas donde no se reconocían términos de aldea singularizados ${ }^{23}$. En los «alijares y términos comunes del Asocio o comunidad de Ávila y su tierra» se incluyen sierras, echos, montes y baldíos comunales, con derechos de pasto efectivos para el ganado del vecindario de la aldea, el de los propietarios en la aldea pero con residencia fuera, es decir, los herederos pertenecientes a la Comunidad de Ávila y su Tierra y el de los vecinos de dicha Comunidad. El acceso a los alijares del ganado de personas ajenas solo podía efectuarse mediante algún tipo de relación contractual o con permiso de los usuarios de derecho (Monsalvo Antón, 2007: 162) ${ }^{24}$.

Los bienes comunales de Ávila y de su Tierra deben relacionarse con los enormes baldíos de realengo que desde las primeras repoblaciones fueron transferidos a los

\footnotetext{
${ }^{21}$ Este mismo fragmento se reproduce en los diccionarios de 1780, 1783 y 1791; en 1783 se añade, tras alixar, la entrada alixares en la que se dice que según Covarrubias es «lo mismo que exidos». En 1803 se define ya simplemente como 'el terreno inculto', con la observación de que «es de uso frecuente en la Jara de Talavera». En esta edición hay a continuación otra entrada alixar que recoge la idea de Covarrubias «lo mismo que exido» y se marca ya como voz antigua. En 1917 alixar remite a alijar, que desde 1609 se refiere al verbo y suele marcarse como voz náutica. No recogemos otros significados que aparecen posteriormente porque no guardan relación con el que nos interesa aquí. El DHLE ${ }^{2}$, s.v. recoge en la definición 2 el siguiente fragmento del Diccionario de Voces Geográficas, c. 1800, «En la Provincia de Segovia se llaman los baldíos alijares, y su aprovechamiento pertenece a todos los pueblos de la tierra».

${ }^{22}$ DLE, s.v. alijar 1,1 m. 'dehesa'. U.m. en pl. 3 m. 'cortijo'. 4 m. desus. 'serranía'.

${ }^{23}$ Según explica este autor (2012-2013: 129, nota 88), se trataba de pastos mancomunados según pactos de vecindad, al margen de que «pudieran establecerse relaciones de tipo contractual». En algunos casos fueron fuente de litigio, como él mismo recoge en el caso del surgido desde 1445 hasta 1494 entre Arenas y Mombeltrán por los alixares de Valdetiétar. Confirma su pervivencia con el mismo carácter en el siglo XV: «Tanto en las cumbres de Gredos y Sierra de El Barco y sus gargantas - la Garganta de los Caballeros, entre otras - como en las riberas del Tiétar - Hontanares, por ejemplo - todavía en el XV alixares indiferenciados, de villa y tierra, persistían y no habían sido adscritos a concejos rurales concretos». En un trabajo anterior (2007: 161) dice que en Ávila los bienes intercomunales se llamaban alixares o común e concejil de Ávila e su tierra.

${ }^{24}$ Señala este autor (2007: 163) que es incorrecto y arriesgado «escindir agricultura y ganadería, o privado y comunal, puesto que lo más sobresaliente era la interconexión entre todo ello»; resalta también la enorme inestabilidad de todo el «entramado agrosilvopastoril» y la «interferencia entre la legalidad comuniega y los derechos de cada pueblo a usar sus términos».
} 
concejos de villa y tierra y comunidades vecinales. Este espacio genérico se fue singularizando en términos y espacios propios de los concejos, pero aun así perduraron muchos baldíos sin otra asignación que la de la ciudad y su tierra y así se mantuvieron en la época bajomedieval. Estos baldíos reciben en la documentación el nombre de alixares, comunes, común e concejil o término e pasto común (Monsalvo Antón, 2002: 171-172):

el dicho Juan Sánchez de L'Adrada, por virtud de la dicha procuración e poder del dicho señor condestable, dixo qu'él que avía tomado la dicha posesión vel casi de todo lo que dicho es, por cuanto dixo que pertenecía al dicho señor condestable, por virtud de la merced qu'el dicho señor rey le avía fecho de los dichos alixares e de las otras aldeas e términos que son en la Trasierra de Ávila, situadas en los dichos alixares, e que avía puesto las dichas forcas e mojones e cruzes por cuanto pertenecía e pertenece al dicho señor condestable. E ambas las dichas partes dexieron que, por que cesen debates e costas e ruidos que dende se podrían re $<$ cre $>$ cer, que eran avenidos en nombre de las dichas sus partes de poner, e posieron en secrestación los dichos términos que los dichos procuradores de la dicha villa d'El Colmenar dexieron que eran demás de los dichos alixares e que pertenecían a la dicha villa ${ }^{25}$ (Lanzahíta, 1432 diciembre 20; AMM, c. 2, n. ${ }^{\circ} 3$ ).

Los testimonios de nuestro corpus, que recogen en varias ocasiones disputas entre distintos lugares y las correspondientes sentencias sobre el uso de los alixares, son muestra de esta situación.

Sepades que por parte del concejo e oficiales e omnes buenos de la nuestra villa d'El Colmenar nos fue fecha relación por su petición, deziendo que ansí en tiempo de don Ruy López e del rey de Navarra como del maestre de Calatrava, señores que fueron de la dicha nuestra villa, siempre usaran de los nuestros alixares de Valdetiétar, ansí en cortar como en pacer con sus ganados como en sembrar pan e pescar en los ríos que en ellos son, sin perturbación de presona alguna nin de pagar tributo nin pena alguna, e qu'el concejo e oficiales e omnes buenos de la nuestra villa de Arenas injusta e non devida mente, non les perteneciendo, a fin de apropiar a sí e para sí los dichos nuestros alixares o la mayor parte d'ellos, se han entremetido e entremeten a prender a los vezinos de la dicha nuestra villa d'El Colmenar e fazer otras sin razones en los dichos nuestros alixares e aún que a los estrangeros que están abenidos para pacer en ellos, por mandado del nuestro recabdador, los prenda e apremian por tal manera que les fazen fazer otros contratos e obligaciones por otras contías de maravedís para ellos ${ }^{26}$ (Mombeltrán, 1453 agosto 1 . AM Mombeltrán, Carpeta 2, n. ${ }^{\circ} 10$ ).

La distribución de la palabra con este sentido parece bastante localizada en la Baja Edad Media, según se desprende de los corpus que hemos manejado. En CODEA+ 2015 hallamos dos testimonios, significativos pero escasos, datados en los años veinte del siglo XVI: alixares en un documento de Riofrío (1520), Ávila, en el que aparece junto a

\footnotetext{
${ }^{25}$ El documento recoge un acuerdo entre el concejo de Mombeltrán y Juan Sánchez de La Adrada, procurador de don Álvaro de Luna, para que los vecinos de Mombeltrán pudiesen pacer en los alijares.

${ }^{26}$ Traslado de una serie de documentos relacionados con los problemas suscitados por el aprovechamiento de los alijares de Valdetiétar entre las villas de Mombeltrán y Arenas; entre ellos se incluye un interrogatorio a testigos presentados por un procurador de Mombeltrán (1445.12.15.- Lanzahíta).
} 
baldíos $^{27}$ y alixar en Trujillo (1528), Cáceres, en coordinación con pasto común ${ }^{28}$. En el corpus del $N D H E$ los ejemplos ${ }^{29}$, al margen de un alixar del rey de Granada, presente en un romance, se sitúan en tierras de Ávila y en la vecina Talavera ${ }^{30}$. En resumen, los no muy abundantes testimonios de $\operatorname{alixar}(e s)$ parecen diatópicamente marcados y reducidos a tierras de Ávila, de Segovia, de Cáceres y de Talavera. A partir de su significado de 'terreno inculto' o 'ejido' pudo especializarse en esta zona para designar los pastos mancomunados entre concejos, sistema habitual en la época, según ha estudiado Monsalvo (2012-2013: 129).

\section{9. $\operatorname{Echo}(s)$}

Terminamos con la voz echo, para la que no hemos encontrado ninguna fuente lexicográfica $^{31}$. No la hemos documentado en testimonios surabulenses sino en los pertenecientes al fondo de la Hispanic Society, algo más norteños, aunque la distancia geográfica es escasa, y en general en series léxicas, en coordinación con palabras que hemos analizado hasta aquí:

Por ende que ellos, en nombre de prior e frailes e convento, suplicavan e suplicaron e pedían e pidieron por merced al dicho concejo, justicia, regidores, cavalleros,

${ }^{27}$ «ningund vezino del dicho lugar ni de otra parte fuese osado fuese osado a cortar, ni roçar ni labrar en los alixares e baldios de la dicha cibdad e su tierra» (CODEA+ 2015: 1432).

${ }^{28}$ «se querelló del dicho prior y frailes y convento diziendo que teniendo y posseyendo la dicha su parte la xara de Alvarnete que es en su término, seyendo alixar y pasto común de los vezinos de la dicha ciudad y su juredición y pacéndola y gozando d'ella como de su alixar en haz y en paz del dicho monesterio» (CODEA+ 2015: 0383).

${ }^{29}$ «salvo demediado março adelante puedan levar la pena por apreçio del ganado que fallaren que les faze daño, e que dende adelante, cogido el frruto, que lo desenbargan e sueltan para sienpre jamás para alixar del duque nuestro señor e pasto a los ganados de sus vasallos. E por quanto este pleyto avía sydo puesto ante el corregidor, los dichos conçejos, Navarredonda e San Martín, se rreçelavan». 1450-1491 Anónimo, "Cuaderno misceláneo en el que se recogen anotaciones de acuerdos del concejo de Navarredonda de Gredos» (Documentación medieval en archivos municipales abulenses) [España].

«no ser en los términos de la dicha villa e no ser deheesa deheessada ni término rredondo, e antiguamente abérsegela dado a los obispos que venían a la dicha villa solamente para que cortasse en ella de ella e ser alixar e pasto común de la dicha villa. E que antiguamente se solía paçer y rroçar e labrar comúnmente por todos los vecinos de la dicha villa e su tierra». 1496 Anónimo, «Los Reyes Católicos mandan cumplir una sentencia» (Documentación medieval en archivos municipales abulenses) [España].

«de la otra parte, el procurador del conçejo de Rriofrío, de y sobre rrazón que la dicha çibdad e su tierra tení an e poseýan quieta e paçíficamente el término que llaman de VValdechoso conmo término baldío e alixar para el bien e pro común de los vezinos de la dicha çibdad e de su tierra e que ynjusta e non devidamente el conçejo de Rriofrío, syn tener derecho nin cabsa, contra voluntad de la dicha çibdad». 1499 Anónimo, «Sentencia en el pleito que mantenían la ciudad de Ávila y su tierra» (Documentación medieval en archivos municipales abulenses) [España].

«tierra rasa, sin monte, porque en todo el termino de este lugar no hay sino el monte de Corralejo, que son pocas encinas y costosas a los que en el cortan, el cual monte es alixar de Talavera y su tierra, aunque está en la dicha dehesa de Corralejo». 1575-1580 Anónimo, Relaciones histórico-geográficas-estadísticas de los pueblos de España. Reino de Toledo [España] [Carmelo Viñas y Ramón Paz, Madrid, CSIC, 1951-1963] Geografía.

${ }^{30}$ Las apariciones de alijar en el mismo corpus (de 1492 a 1992) corresponden todas al verbo: cf. DCECH, s.v. alijarII, 'descargar una nave en todo o en parte', del fr.ant. alegier, aligier (fr. alléger), 'aligerar, aliviar', y éste del lat. tardío ALLEVIARE 'íd'., derivado de LEVIS, 'ligero'. No contamos con testimonios en DITECA.

${ }^{31}$ El NTLLE recoge echo, en unos casos por 'eco' y en otros en el sentido de 'lanzamiento o tiro', como acción de tirar. 
escuderos [...] que les pluguiese mandar que los dichos sus ganados puedan entrar e pacer de aquí adelante en los alixares e montes e sierras, echos e pastos e términos comunes de la dicha cibdad e su tierra e en todo lo baldío d'ella segund que entran e pacen los ganados de los otros vezinos de la dicha cibdad e su tierra, por que ellos puedan sostener los dichos sus ganados (1461 agosto 27 Ávila, Archivo de la Hispanic Society, Monasterio de San Jerónimo de Guisando).

Mandaron que [...] de aquí adelante en cuales quier alixares e echos e montes $e$ sierras e pastos comunes de la dicha cibdad e su tierra e en todos los términos baldíos d'ella segund e por la forma e manera que entran e pueden entrar los ganados de los vezinos de la dicha cibdad e su tierra (1461 agosto 27 Ávila, Archivo de la Hispanic Society, Monasterio de San Jerónimo de Guisando).

De nuevo los testimonios que hallamos en otros corpus parecen concentrarse en Ávila; al menos es lo que muestran el corpus del $N D H E$ y el CORDE ${ }^{32}$. Y es bastante frecuente que pongan de manifiesto el carácter comunal de los echos:

Et otrosí ordena et tiene por bien nuestro señor el rrey que los que tienen los echos de las sierras e de la tierra e de los pastos del término, así conmo de término de Ávila, que los dexen luego libres e desenbargados, por que todos los de la çibdat e de los pueblos e del término, comúnmente, puedan husar dello así conmo de término que es comunalmente de todos.

Dixo este testigo que un echo que es ençima de La Mora, que llaman el echo de ancho Sánchez, fiio de Juan Velásquez, que oyó decir que avía seydo común et conçegil de la dicha çibdat et de su tierra; et quel dicho Sancho Sánchez que lo

\footnotetext{
${ }^{32}$ En el corpus del $N D H E$, para el singular, echo, he revisado las 1858 apariciones hasta 1500 , incluido, y la mayoría corresponde al pasado del verbo echar, y las menos al sustantivo, aunque nunca en el sentido que tratamos, o al Val dEcho. Para el plural echos, hay 257 apariciones, de 1200 a 1997; de nuevo a mayoría corresponden al verbo, por echose, y después al sustantivo, por hechos. Solo los siguientes ejemplos corresponden con el significado buscado y, como puede comprobarse se trata de testimonios abulenses: «E ordenaron que qualquiera que cogere el exido adrede que pague veynte maravedís de pena al conçejo por prueba e pesquisa toda la condiçión de las defesas mayores. E esto consentieron e fezieron con condición si los echos estovieren abiertos e baldíos de aquí adelante conmo agora están día de la fecha desta condición; e si los tornaren a guardar los echos, que se torne el conçejo a ordenar lo que bien viniere». 1450-1491 Anónimo, «Cuaderno misceláneo en el que se recogen anotaciones de acuerdos del concejo de Navarredonda de Gredos» (Documentación medieval en archivos municipales abulenses) [España]. «Hordenamos e mandamos que por quanto algunas personas vesinos e moradores desta cibdad de Auyla e su tierra que tienen ganados, van con ellos a los estremos o a apacentarlos en las deesas e tierras e echos e pastos comunes de la dicha cibdad e su tierra o a otras deesas que tengan avenydas o vengan de los estremos con los dichos ganados o de las dichas tierras e deesas, e son prendados por algunos vecinos» «de oy en adelante todos e qualesquier vesynos desta dicha cibdad e su tierra puedan yr E pasar con sus ganados por qualesquier logares de la dicha cibdad e su tierra a los dichos estremos e tierras e echos e pastos comunes e deessas que touieren arrendados guardando panes e vyñas e prados deesados». 1485, Anónimo, Ordenanzas de Ávila [España] [Marqués de Foronda, Madrid, Real Academia de la Historia, 1917]. En el CORDE recogemos 261 casos de echos en 81 documentos hasta 1600. Las únicas apariciones con el mismo significado se hallan en procesos judiciales de Ávila (1414-1416 y 1478) y en las Ordenanzas de Ávila de 1485 y suman más de un centenar; como ejemplo: «sobre razón de los términos e sierras e pinares e pastos e echos comunes que estavan entrados e ocupados a la dicha cibdat de Ávila e de su tierra» (1414-1416). En CODEA+2015 y DITECA, todas las ocurrencias corresponden a distintos usos de echar o hacer.
} 
avía apropiado e apropia para sy et lo non consiente fazer con sus ganados a los vezinos de la dicha çibdat e de su tierra ${ }^{33}$.

Los echos son también comunales que solían consistir en áreas de pasto con cierto grado de humedad o de altura que, en ocasiones, además de hierba, albergaban piornos y otra vegetación arbustiva y básicamente pertenecían a lo comunal y concejil; eran aptos preferentemente para el pastoreo de ganado vacuno, pero también podían ser objeto de rozas o labores (Monsalvo Antón, 2002: 172).

A pesar de que los corpus que hemos manejado dan cuenta únicamente de los echos abulenses, con la misma denominación y características muy similares están presentes al menos en Andalucía. Carmona Ruiz (1996: 159-160) dice que el echo «era un tipo de acotamiento de naturaleza incierta y que especialmente encontramos en villas situadas en la actual provincia de Cádiz, aunque también aparece en otros concejos del reino de Sevilla, como es el caso de Carmona, Écija o el condado de Niebla» ${ }^{34}$. En opinión de esta autora, el origen de la voz puede relacionarse con una de las características que muestran los testimonios jerezanos: los echos eran «espacios comunales con buenos pastos que se acotaban y anualmente se cedían a los diferentes propietarios de un concejo mediante su sorteo, es decir, se echaban a suerte, para que metieran en ellos sus hatos». Admite que, aunque este fuera su origen y carácter primitivo, con el tiempo la palabra echo se aplicó a cualquier tipo de adehesamiento dentro de una propiedad de mayor tamaño, o a algunas tierras de propios que, a diferencia de los echos concejiles, se arrendaban ${ }^{35}$.

En definitiva, el ordenamiento de los echos abulenses y andaluces muestra diferencias pero coinciden, al menos en su origen, en referirse a espacios comunales de pastos y estar documentados en la etapa bajomedieval.

El DITECA, que recoge bastantes términos del ámbito ganadero, no muestra la presencia de esta voz por lo que es posible que su localización en Andalucía fuera más occidental; quizá la palabra tuviera continuidad por Extremadura, uniendo los testimonios abulenses y andaluces occidentales, aunque de momento no encontramos prueba de ello.

\footnotetext{
${ }^{33}$ Los dos testimonios están tomados del CORDE; el primero, fechado en 1330, es un documento en el que Alfonso XI, de acuerdo con sus oficiales, establece un ordenamiento para la ciudad de Ávila; el segundo, de 1414, pertenece a un proceso judicial entablado por la ciudad de Ávila y los pueblos de su tierra. A propósito de lo que refleja este último documento, es decir, la usurpación de pastos veraniegos por parte de Sancho Sánchez Dávila, señor de San Román y Villanueva, cf. lo señalado por Monsalvo (2007: 164 y 2012-2013: 128 , nota 81 ).

${ }^{34}$ En un trabajo posterior, Carmona Ruiz (2014: 200-202) indica de nuevo que en Jerez los echos eran acotamientos para aprovechamiento comunal del ganado, detalla su frecuente existencia en la zona gaditana y amplía su presencia al concejo sevillano de Matrera, además de los que había mencionado en 1996. Sigue considerando más probable que el nombre se deba al sorteo al que se sometían estos cotos, se echaban a suerte, que al hecho de que fueran lugares en los que se echaba al ganado para pastar o para su reproducción. Aunque hay testimonios que muestran que los echos no siempre eran acotamientos sometidos a régimen de sorteo, esto puede deberse, en su opinión, bien a que anteriormente sí lo hubieran sido, bien a que el término se usara como sinónimo de dehesa.

${ }^{35}$ Las primeras referencias a los echos en el estudio de Carmona Ruiz (1996: 161) proceden de un pleito de términos entablado a finales del siglo XIV entre las villas de Medina Sidonia y Alcalá de los Gazules. Es notable su presencia en testimonios jerezanos del XV.
} 


\section{CONCLUSIONES}

Hemos partido de un corpus limitado y seleccionado una parcela léxica muy concreta. La búsqueda de las palabras en los corpus manejados nos muestra una validez relativa de estos para el estudio de la distribución diatópica de las mismas, pues alguna de las que parecen más locales (conclusión provisional también de momento) no están presentes en corpus pero sí en otras fuentes documentales, como sucede con los echos de la Andalucía occidental.

Las fuentes para el estudio del léxico, desde Covarrubias y el Nuevo Tesoro lexicográfico, hasta el diccionario académico actual o distintas recogidas dialectales, nos han ofrecido información de valor variable según los casos en la interpretación de las voces: no hemos hallado echo como terreno de pastos en ninguna de las fuentes; el Léxico del leonés actual muestra que mangada tiene una extensión más amplia que la marcada en el diccionario académico o la que podemos vislumbrar por su presencia en los corpus.

Otras palabras, del tipo prados y pastos, baldios, montes o dehesas, dada su abundante presencia en la documentación y en la geografía peninsular, están bien atestiguadas e interpretadas en los distintos corpus y fuentes.

Al margen de lo señalado hasta aquí, valorar el carácter sinonímico o cuasi sinonímico de las series en las que se insertan y suman las voces tratadas no habría sido posible sin el trabajo de historiadores de la Edad Media, en especial y en este caso concreto el de los varios estudios de los espacios de pastoreo en Ávila de Monsalvo Antón, citados continuamente; estos estudios nos han permitido conocer una realidad compleja de la época y distinguir el uso privativo y no exclusivamente pecuario de las dehesas, el carácter privado y en algunos casos particular (prado de heno) de los prados, frente a los espacios comunales, montes y sierras, baldios, comunales de aldea, echos, pastos de altura, de propiedad concejil, y alixares, pastos compartidos intercomunales o mancomunados. Solo a partir de estas diferencias llegamos a una interpretación de las series léxicas de las que hemos partido.

Con relación a los posibles diatopismos revisados y con un carácter muy provisional, mangadilla parece ser voz de carácter occidental en la Península; es posible que con distinta extensión, más al sur, lo sea también echo(s); en cuanto a alixar(es), de momento su área de uso parece más reducida, circunscrita a Ávila con continuación por los vecinos Cáceres, Segovia y Talavera, zona esta última para la que, como hemos visto, contamos con noticias de su amplio uso en la segunda mitad del siglo XVIII.

\section{REFERENCIAS BIBLIOGRÁFICAS}

Álvarez Borge, Ignacio (2003): La Plena Edad Media. Siglos XII-XIII, Madrid, Síntesis. ARribas Magro, M. ${ }^{a}$ del Carmen Sonsoles (2012): Las Merindades de Burgos. Un análisis jurisdiccional y socioeconómico desde la Antigüedad hasta la Edad Media, tesis doctoral inédita [en línea], Universidad de Burgos $<$ http://hdl.handle.net/10259/201> [última consulta: 20/06/2019].

CARmona Ruiz, M. ${ }^{a}$ Antonia (1996): «La reglamentación de los echos jerezanos en el siglo $\mathrm{XV} »$, Historia. Instituciones. Documentos, 23, pp. 159-172. 
CARMOnA RuIZ, María Antonia (2014): «Las actividades pastoriles en Jerez de la Frontera: siglos XIII-XIV», en Manuel Antonio Barea Rodríguez, coord., Manuel Romero Bejarano, coord., José Sánchez Herrero, dir., Manuel González Jiménez, dir., 750 aniversario de la incorporación de Jerez a la Corona de Castilla: 1264-2014, Jerez, Ayuntamiento de Jerez, pp. 195-219.

CARrasco CANTOS Pilar e Inés CARRASCo CANTOS (1997): Estudio léxico-semántico de los fueros leoneses de Zamora, Salamanca, Ledesma y Alba de Tormes. Concordancias lematizadas, Granada, Universidad de Granada, 2 vols.

CHARTA = Corpus Hispánico y Americano en la Red de Textos Antiguos, $<$ http://www.corpuscharta.es/consultas.html $>$ [última consulta 28/06/2019].

CODEA+2015: Vid. GITHE.

CORDE = REAL ACADEMIA ESPAÑOLA [en línea]: Corpus diacrónico del español, $<$ http://www.rae.es> [última consulta: 22/05/2019].

Corriente, Federico (2008): Dictionary of Arabic and Allied Loanwords Spanish, Portuguese, Catalan, Gallician and kindred Dialects, Leiden-Boston, Brill-HDO.

COVARRUBIAS, Sebastián de (1987 [1611]): Tesoro de la lengua castellana o española, Barcelona, Alta Fulla.

DCECH = COROMINAS, Joan y José Antonio PASCUAL (2012 [1980-1991]): Diccionario crítico etimológico castellano e hispánico, Madrid, Gredos, CD-Rom.

DEDA = SÁNCHEZ GONZÁLEZ DE HERRERO, María Nieves, dir. (2000): Diccionario español de documentos alfonsies, Madrid, Arco/Libros.

DHLE ${ }^{1}=$ REAL ACADEMIA ESPAÑOLA: Diccionario Histórico de la lengua española (19331936), Madrid, Hernando. T. I: A. 1933 - T. II: B-Cevilla.

DHLE ${ }^{2}=$ REAL ACADEMIA ESPAÑOLA: Diccionario Histórico de la lengua española (19601996), Madrid, Imp. Aguirre. T. I: A-alá. 1960-1972 (fasc. 1-19) - T. II: Álabaantígrafo. 1974-1992 (fasc. 11-20) - T. III: Antigramatical-apasanca. 1993-1996 (2 fasc.) - T. IV: B-bajoca. 1996 (1 fasc.).

DITECA $=$ CARRASCO CANTOS, Inés y Pilar CARRASCO CANTOS, dirs., Diccionario de Textos Concejiles de Andalucía, <http://arinta.uma.es/diteca> [última consulta 10/06/2019].

$D L E=$ REAL ACADEMIA ESPAÑOLA (2014): Diccionario de la Lengua Española, $<$ http://dle.rae.es/?w=diccionario $>$ [última consulta 13/05/2019].

GARCÍA SÁNCHEZ, Jairo Javier (2007): Atlas toponímico de España, Madrid, Arco/Libros.

GITHE (Grupo de Investigación Textos para la Historia del Español): CODEA + 2015 (Corpus de documentos españoles anteriores a 1800), <http://corpuscodea.es/> [última consulta 28/05/2019].

ISASI MARTíNEZ, Carmen, Emiliana RAMOs REMEdIOS y M. ${ }^{a}$ Nieves SÁNCHEZ GonZÁLEZ DE HERRERO (2017): El léxico de los documentos del monasterio de San Salvador de Oña (siglos X-XIII), Coruña, Universidade da Coruña, Anexo 40 de Revista de Lexicografía.

Lamano Beneite, José de (1989 [1915]): Dialecto vulgar salmantino, Salamanca, Diputación de Salamanca.

LE MEN Loyer, Jeannick (2002-2011): Léxico del leonés actual, León, Centro de Estudios e Investigación «San Isidoro».

LíBANO, Ángeles y Consuelo Villacorta (2013): Paisaje rural y explotación agropecuaria. Léxico de los recursos naturales y de la vida cotidiana en el aragonés, navarro y romance vasco (siglos XIII-XVI), Zaragoza, Prensas de la Universidad de Zaragoza.

Llorente Pinto, María del Rosario (1997): El habla de la provincia de Ávila, Salamanca, Caja Salamanca y Soria, Obra social y cultural. 
LÓPEZ DE GUEREÑU, Gerardo (1998 [1958]): Voces alavesas, 2. ${ }^{a}$ edición a cargo de Henrike Knörr, Bilbao, Euskaltzaindia.

MARTín GARCÍA, Gonzalo (1997): Mombeltrán en su historia (Siglo XIII-Siglo XIX), Ávila, Diputación Provincial de Ávila, Institución Gran Duque de Alba.

Monsalvo AnTón, José María (2002): «Espacios de pastoreo de la Tierra de Ávila: algunas consideraciones sobre tipos y usos de los paisajes ganaderos bajomedievales», Cuadernos abulenses, 31, pp. 139-196.

Monsalvo Antón, José María (2007): «Comunales de aldea y comunales de ciudad y tierra. Algunos aspectos de los aprovechamientos comunitarios en los concejos medievales de Ciudad Rodrigo, Salamanca y Ávila», en Ana Rodríguez, ed., El lugar del campesino. En torno a la obra de Reyna Pastor, Valencia, Universitat de Valencia-CSIC, pp. 141-177.

Monsalvo AnTÓN, José María (2009): «La ordenación de los espacios agrícolas, pastoriles y forestales del territorio abulense durante la Baja Edad Media», en Gregorio del Ser Quijano, coord., Historia de Ávila. IV. Edad Media (siglos XIV-XV, segunda parte), Ávila, Institución Gran Duque de Alba, pp. 349-497.

Monsalvo ANTÓN, José María (2012-2013): «Paisajes pastoriles y forestales en tierras salmantinas y abulenses. Aprovechamientos y cambios en los espacios rurales (SS. XII-XV)», Norba. Revista de Historia, 25-26, pp. 105-147.

MoRALA, José Ramón (2007): «Léxico de la vida cotidiana. El trabajo en el campo», en Monarquía y Sociedad en el Reino de León. De Alfonso III a Alfonso VII, León, Centro de Estudios e Investigación San Isidoro, Caja España de Inversiones y Archivo Histórico Diocesano, I, pp. 377-444.

MoRALA, José Ramón (2018): «Léxico agrícola en el Cartulario de Cardeña», en José Antonio Bartol Hernández y José Ramón Morala, eds., El cartulario gótico de Cardeña. Estudios, Salamanca, Fundación Instituto Castellano y Leonés de la LenguaUniversidad de Salamanca, pp. 221-251.

NDHE, cf. REAL ACADEMIA ESPAÑOLA.

NTLLE, cf. REAL ACADEMIA ESPAÑOLA.

ReAl ACADEMIA ESPaÑola (2013-): Nuevo Diccionario Histórico del Español (NDHE) [en línea] <http://web.frl.es/DH> [última consulta 11/07/2019].

REAl ACADEMIA ESPañola: Nuevo Tesoro lexicográfico de la lengua española (NTLLE) [en línea] <http://buscon.rae.es/ntlle/SrvltGUILoginNtlle> [última consulta 19/07/2019].

RIESCO, Pascual (2014): «Formas del parcelario: su huella en la toponimia menor» en Ería: Revista cuatrimestral de geografia. 94, 183-205. <http://dialnet.unirioja.es/servlet/ articulo? codigo $=4835379>$ [última consulta 16/07/2019].

SÁNCheZ GonZÁlez De HerRero, M. ${ }^{a}$ Nieves (2017): «Léxico relacionado con la descripción del espacio en la documentación medieval de Mombeltrán (sur de Ávila)», Revista de Investigación Lingüistica, 20, pp. 261-287.

SÁNCHEZ-PRIETO, Pedro (2010): «Ensayo de geografía lingüística histórica: términos para 'parcela de terreno agrícola' en las fuentes documentales de la Edad Media», en Sara Gómez Seibane y José Luis Ramírez Luengo, comps., Maestra en mucho. Estudios filológicos en homenaje a Carmen Isasi Martínez, Buenos Aires, Voces del Sur, pp. 271-290. 